\title{
La animación a la lectura como estrategia pedagógica para la formación de la competencia literaria en la escuela secundaria*
}

\section{Resumen}

Alrededor de la didáctica de la literatura, se ha formado una constante interrogante en los ámbitos literario y educativo: ¿es posible enseñar a leer literatura a los adolescentes? La pedagogía de la literatura es un campo que ha sido abordado por expertos que se han ocupado del proceso de lectura literaria en la población en cuestión. De acuerdo con lo anterior, en este artículo se hace una reflexión en torno a la educación literaria y, asimismo, se ofrecen posibles respuestas con respecto a un tema de gran importancia en la escuela por medio de la teoría de la recepción, la cual parece ser la más adecuada en la enseñanza de la literatura, al otorgarle prelación a la experiencia estética del lector con el texto literario.

Palabras clave: educación literaria, animación a la lectura, competencia literaria, teoría de la recepción, experiencia estética, escuela secundaria.

Citar: Rojas Camargo, D. J. (julio-diciembre 2018). La animación a la lectura como estrategia pedagógica para la formación de la competencia literaria en la escuela secundaria La Palabra, (33), 129-145. https://doi.org/10.19053/01218530. n33.2018.8818

\section{Derly Juliana Rojas Camargo}

Licenciada en Humanidades e Idiomas, de la Universidad Libre de Colombia. Estudiante de la Maestría en Literatura, de la Universidad Pedagógica y Tecnológica de Colombia. julirocam@gmail.com

*Artículo de reflexión, resultado del trabajo final de la asignatura Pedagogía de la literatura. 


\section{la palabra}

\section{Reading Animation as Pedagogical Strategy for Development of the Literary Competence in High School}

\section{Abstract}

A continuous unanswered question has been asked in the literary and educational fields around literature didactics. Is it possible to teach how to read literature to teenagers? Literature teaching is a field that has been broached by experts who have worked with the mentioned population in the literary reading. According to this, the purpose of this article is to make a brief reflection around literary education, besides, its aim is to offer feasible answers in relation to an important subject in the school through the reception theory, which, it seems to be, the most suitable one in literature teaching, as it gives preference to the aesthetic experience of the reader with the literary text.

Keywords: promotion of reading, literary competence , reception theory, aesthetic experience, secondary school.

\section{L'encouragement à la lecture comme stratégie pour développer la compétence littéraire dans l'enseignement secondaire}

\section{Résumé}

Dans les milieux littéraire et éducatif et, plus particulièrement, en didactique, la possibilité d'enseigner la littérature à des adolescents est une problématique récurrente. Certains spécialistes ont d'ailleurs étudié le processus de lecture littéraire chez le public cité plus haut. Cet article propose ainsi une réflexion autour de l'éducation littéraire et tente de proposer d'éventuelles réponses à cette question de premier plan. Pour cela, nous utilisons la théorie de la réception. Il semble, en effet, que cette dernière soit la plus adaptée pour se pencher sur des interrogations liées à l'enseignement de la littérature parce qu'elle met en avant l'expérience esthétique du lecteur par rapport au texte littéraire.

Mots-clés: éducation littéraire; encouragement à la lecture; didactique de la littérature; compétence littéraire; compétence linguistique; théorie de la réception; expérience esthétique; enseignement secondaire. 
"Creo que el ejercicio de un profesor de literatura es hacer que sus estudiantes se enamoren de una obra, de una página o de una línea si quieren, es decir, que algo quede en su memoria, que algo siga viviendo y ese algo pueda ser citado después con algún error, que es una secreta corrección"

Jorge Luis Borges (1985)

\section{Introducción}

Con frecuencia, se hace alusión a la importancia que la educación literaria tiene en la escuela secundaria para la formación de lectores literarios. Sin embargo, los teóricos que han abordado esta temática, coinciden en la dificultad de lograr tal objetivo. De modo que, se parte de una concepción de literatura como una ciencia compleja, especialmente en lo que concierne a su educación. A pesar de esto, por medio de algunas teorías - entre estas, la teoría de la recepciónse han establecido algunos principios para permitir que los docentes se apropien de su quehacer en la educación literaria, puesto que su instrucción no es una tarea sencilla. El fracaso, en su mayoría de veces, se debe a la utilización, por parte de los profesores, de los enfoques que suelen no ser eficaces ni pertinentes para la escuela secundaria.

La necesidad que tienen los adolescentes de adquirir la competencia literaria, es una habilidad que es indispensable, no solo por cuestiones laborales futuras, sino también por la sencilla razón de que, al concebir a la literatura como un elemento formativo en la educación de los seres humanos, los estu- diantes podrán sacar provecho de ello por medio del placer estético que los textos literarios suelen provocar. Dicha formación es impartida por parte de los docentes en el aula de clase, debido a que estos desempeñan un rol de guía en la educación literaria.

Con base en lo anterior, la relevancia que tiene formar lectores en la escuela secundaria, es inmensa; ya que, al lograr esto, se estará introduciendo al estudiante en un mundo cultural al cual todos los seres humanos, sin discriminación, deberían tener derecho por medio de la literatura, pues, tal como Larrosa (2003), afirma:

De lo que se trata es de que todos tengan acceso al conocimiento entendido como una cosa que hay que repartir de forma igualitaria, que no haya una apropiación restringida, que no sean solo unos pocos lo que se apropien de él para su exclusivo beneficio (p. 33).

La práctica de la lectura en la escuela secundaria, es indispensable por cuanto es inaplazable

Hacer de la escuela una comunidad de lectores que acuden a los textos buscando respuesta para los problemas que necesitan resolver, tratando de encontrar información para comprender mejor algún aspecto del mundo que es objeto de sus preocupaciones, buscando argumentos para defender una posición con la que están comprometidos o para rebatir otra que consideran peligrosa o injusta $[\ldots]$ (Lerner, 2001, p. 26).

Por medio de la literatura, entonces, es posible que los estudiantes hagan parte de una comunidad de lectores en la que, junto con otras personas, compartirán no solo el gusto por las letras, sino también la cultura que ella proporciona, pues según Guimaraes (citado en Higuera, 2016):

La literatura no le impone una cultura al lector, sino que le permite conocer y explorar esa otra cultura. Y a través del reconocimiento del otro, uno puede conocerse y percibirse mejor. En el tema de la lectura y los libros, el poder está en las manos del sujeto: puede aceptarla o rechazarla, puede investigar, puede quererla o no (p. 113).

De acuerdo con lo anterior, al leer, el lector se enriquece intelectualmente, pues aprende nuevos conocimientos. Con respecto a la cultura que propor- 
ciona la lectura, Jiménez (2015) afirma que "la literatura es, por una parte, producto objetivo de la cultura y, por otra, en cuanto que su transmisión depende de su enseñanza y aprendizaje en el sistema educativo y social, conocimiento subjetivo" (p. 214). Al asumir a la literatura como un elemento formativo, se establece una relación entre quien lee y el texto mismo. Con respecto a esto, Larrosa (2003), afirma:

En la formación como en la lectura lo importante no es el texto sino la relación con el texto. Y esa relación tiene una condición esencial: que no sea de apropiación, sino de escucha. $\mathrm{O}$ dicho de otro modo, que lo otro permanezca como otro y no como «otro yo» o como «otro desde mí mismo» (p. 30).

En este orden de ideas, en primer lugar, se abordará la competencia literaria y la competencia lingüística, y la relación inherente entre ambas; en segundo lugar, se hará una aproximación a los enfoques que se suelen utilizar para el estudio de la literatura; en tercer lugar, se hará mención a una estrategia, a modo de propuesta, para la educación literaria en la escuela secundaria. Finalmente, se realizarán conclusiones a partir de las argumentaciones presentadas a lo largo del presente artículo.
La competencia lingüística y la competencia literaria: relación inherente

El desarrollo de la competencia lingüística es de vital importancia dentro de la adquisición de la competencia literaria, puesto que esta permite una interpretación adecuada del texto literario. Con respecto a esta competencia, Chomsky (1965), afirma que:

La teoría lingüística se centra principalmente en el hablante-oyente ideal de una comunidad de habla completamente homogénea que conoce su lengua perfectamente $\mathrm{y}$ al que no le afectan condiciones irrelevantes a nivel gramatical como las limitaciones de memoria, las distracciones, los cambios de atención y de interés y los errores al aplicar su conocimiento de la lengua a la actuación real (p. 3).

Así las cosas, el hecho de que los estudiantes de secundaria posean esta competencia es importante, puesto que ello les permitirá "producir y reconocer los enunciados como gramaticalmente válidos o no" (Ministerio de Educación Nacional, 1998, p. 24). La educación literaria pretende ofrecer la adquisición de la competencia literaria. Para Culler (1975), la competencia literaria es:

El conjunto de convenciones para leer los textos literarios.
$Y$ tras esa concisa definición, advierte que la problemática que supone hablar de competencia literaria implica la distinción entre lectores competentes y lectores menos competentes, en correlación con su capacidad para realizar una lectura correcta (p. 169).

Los postulados de Culler con relación a la competencia literaria, resultan oportunos, por cuanto

El lector debe convertir las secuencias lingüísticas en estructuras con significado literario; la existencia de diversos géneros literarios le permite al lector comprender el proceso de naturalización de la obra, o en otras palabras, su historicidad le permite al lector entrar en diálogo con la tradición literaria (Carvajal y Moreno, 2009, p. 27).

Para Eco (1993), el lector debe tener ciertas habilidades, entre las que cabe mencionar: una "serie de competencias (expresión más amplia que "conocimiento de los códigos») capaces de dar contenido a las expresiones que utiliza. Debe suponer que el conjunto de competencias a que se refiere es el mismo al que se refiere su lector" (p. 80); de esta manera, el autor "deberá prever un Lector Modelo capaz de cooperar en la actualización textual de la manera 
prevista por él y de moverse interpretativamente, igual que él se ha movido generativamente" (p. 80). Así las cosas, el autor da por sentado que el lector que lee su obra posee una serie de competencias que le permitan decodificar el código propuesto por este. Más adelante se volverá a la temática del lector modelo, propuesta por Eco.

Existe una relación de interdependencia inseparable entre lengua y literatura, pues

La literatura es un conjunto de producciones resultado del uso estético de la lengua; sus obras constituyen exponentes de aplicación o producción lingüística, según factores y convenciones culturales centrados en la combinación de aspectos de la lingüística y de las teorías de la recepción y de la intertextualidad (Mendoza, 2008, p. 256).

La competencia literaria se puede considerar como una habilidad necesaria para el aprendizaje de la competencia lingüística, es decir, la primera facilita el estudio de la segunda. Por consiguiente, como se afirmó anteriormente, la relación que existe entre ambas competencias es inherente. El uso del texto literario como recurso en la enseñanza de la lengua, resulta pertinente, pues le permite al estudiante adquirir determinado léxico que, en un comienzo, le puede parecer ajeno. Según esto, Rodríguez (1977), afirma:

La correspondencia entre la lingüística y la literatura emana del objeto mismo de estudio que es el lenguaje, pues siendo la lingüística la ciencia del lenguaje, la literatura debe ser considerada como una de las manifestaciones sui generis de la lengua (p. 44).

A lo largo de la historia, la literatura "ha ejercido un papel preponderante como eje central no solo de la enseñanza lingüística sino de la formación literaria y la huella que esta ha dejado en las mentes de los estudiantes" (Bolívar y Gordo, 2016, p. 203). De manera que, la relación existente entre ambas competencias ha sido, generalmente, abordaba en conjunto. Entonces, no es una casualidad que, en la mayoría de instituciones educativas colombianas, la asignatura de lengua castellana se enseñe junto con la de literatura, fusionadas en una sola asignatura.

La incomprensión de un texto literario significa la ausencia de informaciones, tanto lingüísticas como literarias; por consiguiente, es imperioso que el estudiante se encuentre en capacidad de hacer uso adecuado de las reglas; es decir, emplearlas pragmáticamente, lo cual incluye la posesión de factores, tales como: uso, contextualización, convencionalismos socioculturales, experiencia de mundo, entre otras (Mendoza y Pascual, 1988). Estos elementos le permitirán al estudiante, la adquisición de la competencia literaria.

Durante los años sesenta y setenta, los objetivos de adquisición de conocimiento para desarrollar la competencia literaria fueron reemplazados por la formación de instrumentos interpretativos (Colomer, 2001); es decir, se le dio prelación a la interpretación más que al saber. En consecuencia, hubo una revolución literaria, pues el acercamiento a obras literarias pasó a ser el asunto de mayor importancia junto con prácticas de lectura en donde el uso de la literatura fue especialmente social (Colomer, 2001). Este avance renovó la concepción de literatura que se tenía en la escuela, puesto que era más imperioso y urgente leer los libros que elaborar críticas sobre ellos. Con respecto a esto,

la idea de que un niño cuando sale del liceo ha de «saber» literatura es una de las más absurdas que conozco: la literatura, para la mayor parte de las personas, no ha de ser un objeto de conocimiento positivo, sino un instrumento de cultura y una fuente de placer (Lanson citado en Colomer, 2001, p. 7). 
De acuerdo con lo anterior, la literatura no debe ser un artilugio del cual una persona deba vanagloriarse, sino que debe, especialmente, suscitar placer al lector; ello garantiza que, después de haber leído la obra literaria, el lector no vuelva a ser el mismo. De lo contrario, no habrá existido la experiencia estética mencionada anteriormente, pues "la presencia de una competencia literaria solo es posible constatarla a partir de los efectos -comprensión, reconocimiento estético, actitud lúdica, goce artístico o intelectual...-que el mensaje provoca en el lector" (Mendoza, 2004, p. 138).

En cuanto se menciona el término de «competencia literaria», es necesario, asimismo, mencionar la noción de intertexto, pues "en cuanto a que la educación literaria está centrando su atención en el proceso y la actividad del lector, en la participación de este en la interpretación de un texto literario" (Perdomo, 2005, p. 149). Según esto, se presentan, entonces, las relaciones transtextuales. Existen cinco tipos de relaciones. La primera es la intertextualidad, la cual es definida por Genette (1989) como "una relación de copresencia entre dos o más textos, es decir, eidéticamente $\mathrm{y}$ frecuentemente, como la presencia efectiva de un texto en otro" (p. 10). Esta se da por medio de la cita, del plagio y de la alusión. En otras palabras, el lector debe estar en la capacidad de realizar asociaciones, inferencias, transposiciones y generalidades literarias (Mendoza, 2008). De manera que, lo que le permite al lector comprender es el hábito lector; en otras palabras, la experiencia de lectura del lector le permite validar o no al texto. La segunda es el paratexto, que hace referencia a la relación menos explícita y más distante; es decir, los títulos, subtítulos, epígrafes, prólogos, epílogos, etc. La tercera se refiere a la metatextualidad, la cual une un texto a otro texto convocándolo. La cuarta es la hipertextualidad, que hace alusión a toda relación que une un texto B (hipertexto) a un texto anterior A (hipotexto). La quinta y última relación transtextual, es la architextualidad, que se refiere a una relación muda que hace alusión a una mención paratextual taxonómica; es decir, a una clasificación de géneros (Genette, 1989).

En definitiva, la relación que se establece entre la lingüística y la literatura es inmanente, puesto que la primera desempeña un papel importante en la adquisición de la habilidad lectora de los estudiantes; pues, por ejemplo, el lingüista y filólogo ruso Roman Jakobson "sustentó la tesis de que no hay razón para separar literatura y lingüística: si la primera constituye el arte de la creación verbal, la segunda es -por excelencia- la ciencia encargada de estudiar el lenguaje verbal, en todas sus manifestaciones" (Kirchof, 2009 , p. 61). De acuerdo con esta proposición, es inútil intentar aislar a ambas disciplinas.

Los enfoques para los estudios literarios

El rol del docente como intermediario-crítico en la enseñanza de la literatura, es el de vínculo entre el estudiante y la obra literaria; en otras palabras, es el que favorece la comunicación entre ambas partes, haciendo las veces de mediador, pues "el enamoramiento, el despertar es hoy responsabilidad de la escuela, y la escuela estableció al mediador en la figura del profesor" (Bolívar y Gordo, 2016, p. 204). Asimismo, es quien, por medio de diversos enfoques, lleva a cabo el estudio de dichas obras. En este orden de ideas, Bolívar y Gordo (2016), afirman que "es por ello que, el maestro debe ser un provocador permanente que planea procesos de lectura que impliquen la argumentación y la crítica, de manera que permita al estudiante ejercer su creatividad, argumentación, interpretación y producción” (p. 204).

Con respecto a los enfoques utilizados por los docentes para abordar el estudio de la literatu$\mathrm{ra}$, en primer lugar, se encuentra el método formal, el cual "no resulta de la constitución de un 
sistema «metodológico» particular, sino de los esfuerzos por la creación de una ciencia autónoma y concreta" (Todorov, 1978, p. 21). Lo que los formalistas deseaban estudiar era la «literariedad» de una obra; es decir, qué es lo que hace que un texto sea literario, más allá de los aspectos sociológicos, psicológicos, filosóficos, etc., que rodean a la obra literaria. Para los formalistas, el tema de la forma es fundamental para la vida, pues la forma remite a la experiencia estética. En segundo lugar, se encuentra el enfoque del estructuralismo, que "se interesa en las estructuras, más concretamente, en el estudio de las leyes generales que regulan fenómenos individuales a meros ejemplos de esas leyes" (Eagleton, 1988, p. 60). Para el estructuralismo, la obra es un sistema que tiene leyes de combinación; el texto literario no está hecho en el lenguaje cotidiano y lo estructural tiene que ver con la historia y el discurso. El estructuralismo considera al relato como un artefacto y se pregunta ¿qué es lo que hace verosímil a un texto?; estructuralmente, ¿qué favorece la verosimilitud?, ¿desde qué perspectiva se ve el mundo?

Otro de los enfoques para el estudio de la literatura, es la semiótica, que comienza a desempeñar un papel fundamental en la educación literaria, y hace re- ferencia al "estudio sistemático de los signos" (Eagleton, 1988, p. 64). Para la semiótica, los actos humanos están dictaminados socialmente, pues, dentro de una comunidad, la manera como los miembros actúan puede ser aceptada o rechazada, de acuerdo con los códigos que se manejen internamente. Antaño, en la semiótica literaria, se solía privilegiar al autor, a la época y a otros elementos externos, pues se creía que el significado de la obra se encontraba precisamente en los componentes que rodeaban al autor. Desde una óptica semiótica, la lectura se define como "decodificación del texto, como recreación de los significados, a partir de la participación del lector. El texto se plantea como un acto comunicativo entre el autor como productor y el lector como descodificador del mismo" (Castro y Posada, 1994, p. 147).

Al considerar a la población escolar, la mayoría de estos enfoques no siempre resultan adecuados para llevar a cabo la educación literaria en la secundaria; sin embargo, su manera de proceder no debe ser descartada por completo. De otro modo, entre los enfoques que, al parecer, resultan más eficaces, es posible mencionar al de la teoría de la recepción. En esta, intervienen tres factores: el autor, la obra y el público, en el que "la noción de recepción es entendida en el doble sentido de la acogida (o aprobación) e intercambio" (Jauss, 1981, p. 34). De otro modo, la palabra «estética» ya no hace hincapié en la belleza de algo, sino que se refiere propiamente a

¿Cómo aprender algo sobre el arte a través de la experiencia artística misma, a través de la consideración histórica de la práctica estética que, con las actividades de producción, recepción y comunicación, está en la base de todas las manifestaciones del arte? (Jauss, 1981, p. 34).

La utilización de la estética de la recepción en la educación literaria en la escuela secundaria, resulta pertinente, por cuanto "restituye el rol activo del lector en la concretización sucesiva del sentido de las obras a través de la historia" (Jauss, 1981 , p. 35). Una de las ventajas que proporciona el uso de esta teoría para los estudios literarios, radica en que "el lector no lee solamente a partir de sus propias impresiones y experiencias; en el acto de lectura, el lector también sale de sí mismo para comprender al otro a través del distanciamiento que el texto le propone" (Higuera, 2016, p. 192). Esto quiere decir que el papel que el lector adopta es el de la empatía, puesto que se deconstruyen los roles de sujeto y objeto, fusionándose en uno. Como lo afirma Iser (1975), 
El proceso de lectura implica el borramiento temporal de la separación entre objeto y sujeto; el llenar los espacios vacíos-producidos por técnicas de distanciamiento-, el lector comprende a los otros y a sí mismo; el acto de lectura adquiere entonces una connotación fenomenológica, hermenéutica y humanística (p. 309).

La estética de la recepción es la modalidad más reciente de la hermenéutica alemana. Al estudiar el papel del lector en la literatura, permite que este realice conexiones implícitas, saque inferencias y ponga a prueba sus presentimientos. Para la teoría de la recepción, toda obra literaria está constituida por espacios en blanco; en otras palabras, la obra está llena de indeterminaciones. De otro modo, la teoría de la recepción no funciona con todas las obras, pues, por ejemplo, es relativa la manera como se interpreta un poema, mientras que un aviso suele no ser ambiguo. En este tipo de lectura de la obra, el proceso es siempre dinámico; un movimiento complejo que se desarrolla en el tiempo. El lector se convierte en un sujeto que elige y organiza ciertos elementos en cierta forma.

La teoría de Iser (1975), se basa en una ideología liberal humanista: creer que en la lectura debemos ser flexibles, receptivos, imparciales; preparados para poner en tela de juicio nuestros criterios, y permitir que se transformen. Iser (1975), piensa que un lector con firmes convicciones ideológicas hace que no sea un buen lector, puesto que no es capaz de expandir su pensamiento. Así las cosas, es necesario ser liberal para leer literatura; de manera que, si el lector tiene una mente cerrada, no podrá analizar la obra estética y, por tanto, no podrá obtener una experiencia satisfactoria del texto. Dicho de otra forma, el lector debe procurar acoger al texto. Por lo tanto, un lector intransigente, es

Ese lector arrogante que se empeña en permanecer erguido frente a lo que lee. Es el sujeto que resulta de la formación occidental más agresiva, más autoritaria. Es el hombre que reduce todo a su imagen, a su medida; el que no es capaz de ver otra cosa que a sí mismo; el que lee apropiándose de aquello que lee, devorándolo, convirtiendo todo otro en una variante de sí mismo (Larrosa, 2006, p. 97).

Gracias a la teoría de la recepción, el contacto entre el lector y el texto se ha consolidado por medio de la lectura compartida. La lectura colectiva resulta pertinente en la escuela secundaria, pues facilita "el referente común necesario para ejercitar la competencia literaria con la ayuda del profesor y del resto de lectores en los aspectos de construcción global de la obra, aspectos imposibles de analizar en fragmentos aislados" (Colomer, 1991, p. 24). Tanto para Colomer (2005) como para Rosenblatt (2002), la lectura compartida se configura como la base para la formación de lectores en la escuela.

El papel del lector en la significación de la obra es clave, puesto que, por ejemplo, para Eco (1993), el lector se convierte en un sujeto activo en la interpretación del texto y de sus relaciones con el emisor; de este modo, el lector denota por medio de unos signos lingüísticos, pero, asimismo, connota, pues infiere significados diferentes dentro del texto. Entonces, la tarea del lector consiste en llenar los espacios en blanco; dicho de otro modo: indaga con respecto al significado del texto, para así lograr decodificar lo que el autor quiere dar a entender. Para que esto suceda, el autor configura, de acuerdo con Eco (1993), a un lector modelo que posea la competencia lingüística, que le permita anticiparse a los hechos, así como inferir; tal y como funciona con la literatura policíaca, como es el caso de Edgar Allan Poe con Los crímenes de la calle Morgue; Arthur Conan Doyle, con Las aventuras de Sherlock Holmes; y Robert Louis Stevenson, 
con El extraño caso del Dr. Jekyll y Mr. Hyde, por citar algunos ejemplos.

La estética de la recepción, junto con la semiótica y la pragmática "se refirieron ampliamente al papel cooperativo que el texto otorga al lector y a la literatura como uso específico de la comunicación social" (Colomer, 2001, p. 4). En consecuencia, la articulación de un texto depende de su receptor. Según esto, el lector comienza a involucrarse directamente con la obra literaria; su rol, por lo tanto, se ve transformado. De esta manera, la literatura ofrece la posibilidad de representar la vida del lector, ya que, de acuerdo con Petit (1999), "la lectura puede ser, justamente, en todas las edades, un camino privilegiado para construirse uno mismo, para pensarse, para darle un sentido a la propia experiencia, un sentido a la propia vida" ( $p$. 74). Al concebir la lectura como un elemento formativo, Larrosa (2003), afirma que:

Pensar la lectura como formación implica pensarla como una actividad que tiene que ver con la subjetividad del lector: no solo con lo que el lector sabe sino con lo que es. Se trata de pensar la lectura como algo que nos forma (o nos de-forma o nos transforma), como algo que nos constituye o nos pone en cuestión en aquello que so$\operatorname{mos}$ (p. 25).

Con la finalidad de que la lectura se convierta en formación, "es necesario que haya una relación íntima entre el texto y la subjetividad" (Larrosa, 2006, p. 96). De manera que, el sujeto debe mantener un vínculo estrecho con la obra. Entonces, si la lectura es entendida como un proceso subjetivo, la imaginación que esta suscita se da por medio de la experiencia personal del lector; es decir, por medio del hábito de leer, puesto que "llegar a conocerse mejor, poder pensarse en su subjetividad, y mantener un sentimiento de individualidad, cobra una importancia aún mayor" (Petit, 1999, p. 75). Otra de las funciones de la literatura es que ayuda a reducir el analfabetismo en la población, puesto que, siguiendo las ideas de Yepes (2016),

En la literatura está todo el universo, están todas las épocas y modos de vida, porque en la literatura se encuentran todos los tratados económi$\cos$ y sociológicos expresados desde las veleidades y prácticas humanas, porque sencillamente esta refleja la existencia de seres que padecen de injusticias y desatinos (p. 7).

En este punto, la literatura adquiere un carácter político en el que es posible formar ciudada- nos pensantes y autónomos, por cuanto

Compromete los sentidos, deleita y lastima, pero en esencia nos dota de una aguda observación del mundo, del cómo se vive mal, del cómo se podría vivir bien, la literatura se lo dilucida a los lectores y los dispone como seres políticos (Yepes, 2016, p. 7).

Es necesario entonces, la creación de nuevas políticas para que la literatura sea un elemento que se arraigue en la vida de las personas, y de esta manera, sea la «culpable» de la ilusión de los ciudadanos. En este punto, la literatura, abordada desde la estética de la recepción, entra a desempeñar un papel fundamental en la didáctica de la literatura, pues, además de suscitar una experiencia grata, también es posible que el adolescente halle un alivio a su realidad, por cuanto "los libros son también compañeros que consuelan, y en ellos encontramos a veces palabras que expresan lo más secreto, lo más íntimo que hay en nosotros" (Petit, 1999, p. 76).

Toda obra contiene, en clave, lo que Iser (1975) llama «lector implícito». Es posible que el autor no se haya fijado en un tipo particular de lector, incluso, hasta le puede ser indiferente quien lea su obra; no obstante, 
cierto tipo de lector está incluido en el mismo hecho de escribir. De otro modo, el estudiante debe estar en la capacidad de hacer una distinción entre el autor y el narrador, ya que, en muchas ocasiones, el alumno tiende a confundir al autor real con el autor implícito (Chatman, 1978). Así, por ejemplo, cuando están leyendo un cuento de Julio Cortázar, creen que el narrador es, en realidad, el mismo Cortázar.

El lector del texto es quien le da sentido al mismo, y solo este se encuentra en condiciones de juzgar la esteticidad de la obra literaria de acuerdo con la interpretación que le otorgue. Este es un ejercicio totalmente subjetivo que no puede adherirse a opiniones externas. En consecuencia, Eco (1992) afirma:

Un texto es un artificio cuya finalidad es la construcción de su propio lector modelo. El lector empírico es aquel que formula una conjetura sobre el tipo de lector modelo postulado por el texto. Lo que significa que el lector empírico es aquel que intenta conjeturas, no sobre las intenciones del autor empírico, sino sobre las del autor modelo. El autor modelo es aquel que, como estrategia textual, tiende a producir un determinado lector modelo (p. 41).

Con respecto al lector modelo, Eco (1993), afirma que "es un conjunto de condiciones de felicidad, establecidas textualmente, que deben satisfacerse para que el contenido potencial de un texto quede plenamente actualizado" (p. 89). En otras palabras, el lector modelo debe estar en capacidad de desentrañar el código que el autor propone en su texto; esto se da, como ya se afirmó con anterioridad, por medio de una serie de competencias que le permitan al lector convertirse en el receptor ideal de la obra.

En definitiva, la teoría de la recepción estudia el papel del lector en la literatura, en donde "el lector «concretiza» la obra literaria, la cual, en sí misma, no pasa de ser una cadena organizada de signos negros estampados en una página" (Eagleton, 1988 , p. 50), y según la cual "el proceso de lectura es siempre dinámico, es un movimiento complejo que se desarrolla en el tiempo" (Eagleton, 1988, p. 51). Así, los factores que intervienen en esta teoría son tres: el autor, la obra y el público, lo cual quiere decir que se lleva a cabo un proceso de intermediación dialéctico (Jauss, 1980).

La propuesta de la animación a la lectura como estrategia para la lectura literaria

A menudo, se suele abordar el tema de «enseñar» literatura en la escuela; sin embargo, para que esto sea posible primero es necesario transmitir el interés por la literatura, en lugar de enseñar contenidos sobre la misma, ejercicio que suelen hacer la gran mayoría de docentes en el aula; de ahí, el motivo de su fracaso al intentar impregnar a los estudiantes el amor por las letras. De modo que, una estrategia que puede resultar bastante útil para la enseñanza de la literatura en la escuela, es la táctica de la animación a la lectura, la cual se refiere a "una acción que crea un vínculo entre el material de lectura y el individuo. Es de tipo pedagógico y se trata de darle ánima/alma al texto (Juegos literarios, club de lectura, tertulias...)" (Red de Bibliotecas, 2012, p. 2). De acuerdo con Yepes (2016), en esta actividad

Se crea un espacio de encuentro alrededor de un texto determinado en el cual se escucha la palabra de unos y se percibe el silencio de otros como derecho natural a no decir nada, a negarse a hacer algo extraño a sus naturalezas (p. 4).

Para llevar a cabo este ejercicio, es necesario que existan espacios proporcionados por las bibliotecas; así, el profesor podrá recomendar a los estudiantes que asistan a un ambiente propicio para que la animación a la lectura sea un puente que permita el contacto con la lectura literaria. Yepes (2016), afirma que, de esta forma se despierta una conciencia y los estudiantes estarán en capacidad de expre- 
sar sus opiniones de una forma confiada. Conseguir que lo anterior se lleve a cabo, no es tarea sencilla. Por lo tanto, es un reto que los profesores deberían afrontar para suscitar en sus estudiantes la misma pasión que estos tienen por las letras. Al hacerles comprender esto a los alumnos, la educación literaria puede llevarse de una manera mucho más amena y menos monótona. Es necesario tener en cuenta que no es posible enseñar el sentimiento estético literario, en razón a que "el acto artístico es un acto creador y no puede reproducirse mediante operaciones puramente conscientes [...] no se puede enseñar el acto creador del arte; pero ello no significa que el educador no pueda contribuir a su formación y manifestación" (Vigotsky, 1972, p. 314). Por consiguiente, el rol del profesor es la formación de las bases para que los estudiantes desarrollen el sentimiento estético. No obstante, "los sentimientos producidos por la literatura se experimentan en lo íntimo y constituyen la respuesta afectiva que mueve al lector internamente. No se pueden enseñar porque el acto de la sensación literaria es personal e intransferible" (Altamirano, 2016, p. 158).

Así las cosas, el placer estético es algo que no se puede enseñar, puesto que el "placer del texto es ese momento en que mi cuerpo comienza a seguir sus propias ideas -pues mi cuerpo no tiene las mismas ideas que yo-" (Barthes, 1982, p. 29). Esto quiere dar a entender que el sentir del cuerpo no es lógico ni racional, por cuanto la experiencia estética lectora se escapa de las explicaciones. El sentimiento estético es imposible de enseñar ya que es una experiencia individual $\mathrm{y}$, por tanto, subjetiva. Para Jauss (1992), la importancia del placer radica en "la rendición sensual directa del yo ante un objeto" (p. 30). Yepes (2016), opina que el papel que desempeña la literatura en la vida de los seres humanos, es el de ayudarles a su propia transformación, por cuanto la experiencia estética hace que, una vez adquirida, el individuo no vuelva a ser el mismo; en otras palabras, será un sujeto tentado por el arte.

Para Larrosa (2006), la experiencia es:

Un movimiento de ida y vuelta. Un movimiento de $i d a$ porque la experiencia supone un movimiento de exteriorización, de salida de mí mismo, de salida hacia fuera, un movimiento que va al encuentro con eso que pasa, al encuentro con el acontecimiento. $\mathrm{Y}$ un movimiento de vuelta porque la experiencia supone que el acontecimiento me afecta a mí, que tiene efectos en mí, en lo que yo soy, en lo que yo pienso, en lo que yo siento, en lo que yo sé, en lo que yo quiero, etcétera (p. 90).
Con respecto a la lectura como experiencia, Larrosa (2003), afirma que:

La experiencia ya no es lo que nos pasa y el modo como le atribuimos sentido, sino el modo como el mundo nos vuelve su cara legible, la serie de regularidades a partir de las que podemos conocer la verdad de lo que son las cosas y dominarlas (p. 35).

Entonces, la experiencia de la lectura como tal, es un «principio de transformación» porque el sujeto está en constante cambio, en donde la consecuencia es, precisamente, la transformación del individuo. No obstante,

Mostrar una experiencia no es enseñar el modo como uno se ha apropiado del texto, sino cómo se le ha escuchado, de qué manera uno se ha abierto a lo que el texto tiene que decir. Mostrar una experiencia es mostrar una inquietud. Lo que el profesor transmite, entonces, es su escucha, su apertura, su inquietud (Larrosa, 2006, p. 100).

De acuerdo con esto, compartir la experiencia estética que suscita la literatura puede resultar favorable; sin embargo, existe una gran brecha entre compartirla con los estudiantes, a condicionarlos a que experimenten lo mismo que el profesor. Debido a esto, es importante no caer en un dogmatismo literario, puesto que, en algunas ocasiones, esta puede ser la razón por 
la que los estudiantes sientan cierto rechazo por la lectura. En consecuencia, las imposiciones, más que ayudar al proceso de la educación literaria, pueden entorpecerla. Por lo tanto, si el lector, después de leer un libro "se mira al espejo y no nota nada, no le ha pasado nada, es un lector que no ha hecho ninguna experiencia" (Larrosa, 2006, p. 92). Entonces, es necesario hacer énfasis en el hecho de que la lectura es una experiencia que, se supone, debería hacer que el lector, después de leer la obra, no vuelva a ser el mismo. Con respecto a esto, Kafka (citado en Larrosa, 2006) afirma:

Si el libro que leemos no nos despierta como un puño que nos golpeara en el cráneo, ¿para qué lo leemos? ¿Para que nos haga felices? Dios mío, también seríamos felices si no tuviéramos libros, y podríamos, si fuera necesario, escribir nosotros mismos los libros que nos hagan felices. Pero lo que debemos tener son esos libros que se precipitan sobre nosotros como la mala suerte y que nos perturban profundamente, como la muerte de alguien a quien amamos más que a nosotros mismos, como el suicidio. Un libro debe ser como un pico de hielo que rompa el mar congelado que tenemos dentro (p. 94).

Una de las tácticas por medio de las cuales se pueden llevar a cabo la animación a la lectura, es el contagio literario, el cual hace referencia a "transmitir un sentimiento estético por la literatura a través de la provocación literaria para despertar el entusiasmo por la lectura literaria con el fin de que el lector viva y disfrute la verdadera literatura de manera directa y personal" (Altamirano, 2012, p. 26). De modo que, hay que procurar conseguir que los estudiantes, en efecto, comprendan de esta manera a la literatura, para que la adquisición de la competencia literaria en la escuela deje de ser una utopía y se convierta en una realidad. Ello permitirá formar lectores que en realidad aprecien las letras y quienes, al culminar sus estudios secundarios, se encuentren en capacidad de ser literariamente competentes, cualidad de la cual se verán beneficiados tanto en su vida profesional, como personal.

El objetivo principal del contagio literario es la sensibilización de los sentidos, cualidad que se ha ido perdiendo con el tiempo. Esto se debe a que a los jóvenes, en la actualidad, les importan menos los sentimientos que en otras épocas, puesto que todo lo ven como algo remilgado y ridículo; les cuesta expresarse a causa de que la mayoría de asuntos los encuentran como algo nimio. Por ende, a la literatura, que es un arte, al igual que la música, en donde debe existir un tipo de sentimiento especial, la consideran como algo aburrido debido a la falta de interés y pasión. Aquí es donde el profesor entra a desempeñar un rol fundamental como guía entre los estudiantes y la literatura. Para que los estudiantes desarrollen una competencia literaria, primero es necesario que se les anime a la lectura y el contagio literario es una buena alternativa para llevar dicho ejercicio.

El contagio literario está estrechamente ligado con la teoría de la recepción, por cuanto ambas abordan la esteticidad como eje central. De acuerdo con Altamirano (2016), "la primera tarea de la didáctica de la literatura ha de ser la formación de la sensibilidad literaria de los estudiantes a través de la lectura directa de los textos" (p. 157). Entonces, el profesor de literatura es quien procura que el sentimiento estético se despierte en sus estudiantes. Esta consideración nace por parte de autores como Vladimir Nabokov, Jorge Luis Borges y Julio Cortázar, quienes tienen en común el haber sido profesores de literatura y quienes en "el ejercicio de la educación literaria, tienen como objetivo principal transmitir la pasión por la literatura con el fin de que los estudiantes gocen con el arte verbal así como lo han hecho ellos" (Altamirano, 2016, p. 158). Así las cosas, transmitir la literatura resulta un ejercicio, aunque en ocasiones difícil, gratificante para un profesor. De acuerdo con Argüelles (2009), 
Un adulto que disfruta el placer de leer contagia ese placer, incluso sin proponérselo deliberadamente, en otros adultos y, sobre todo, en sus hijos niños, adolescentes o jóvenes que, a partir del ejemplo, sin sermones, sin discursos severos, es bastante probable que se interesen en descubrir qué es lo que hay en esos objetos llamados libros que tanto atraen a su padre (p. 219).

En definitiva, el docente, en su calidad de adulto, puede, con dedicación, lograr tal objetivo, pues puede hacer las veces de un gestor cultural. Así, el contagio de la literatura podría llegar a ser un éxito en la educación literaria en la escuela secundaria.

\section{Conclusiones}

Como resultado de todo lo expuesto anteriormente, se considera que es posible enseñar a leer literatura a los jóvenes por medio de la teoría de la recepción con una base semiótica. De lo contrario, se estaría cayendo en un adoctrinamiento dogmático en la escuela secundaria, puesto que los estudiantes deben tener el

Derecho de leer y el de no leer, el derecho de saltarse las páginas, a no acabar un libro, a releer, a leer cualquier cosa, en cualquier sitio, en voz alta o picotear entre sus páginas, para concluir con el derecho de no hacer comentarios (Mendoza, 2008, p. 4).
Por su parte, el docente de literatura, como vínculo entre el estudiante y la literatura, estimula el interés de estos, dado que, como ya se afirmó, el docente desempeña el rol de mediador por cuanto "el papel de los mediadores se establece como crucial debido a que propicia anhelo e ilusión y genera, en muchas ocasiones, motivación y amor por lo literario" (Bolívar y Gordo, 2016, p. 208). Por lo tanto, lo que más debe evitar el profesor es caer en un impresionismo incuestionable, porque el currículo así lo dictamina, a causa de la concepción que se tiene de la enseñanza de la literatura en la que "se debe leer a esos grandes autores por su valor formativo y por su función de modelos" (García Gual citado en Mendoza, 2008, p. 1). Con respecto a esto, lo ideal sería no solo leer a los llamados «clásicos», sino también libros con temáticas de interés para los estudiantes. La literatura juvenil se presenta como una buena alternativa para comenzar con la educación literaria; luego, con el paso del tiempo, y el posterior afianzamiento de la competencia literaria, se podrá abrir el abanico de opciones literarias al estudiantado.

El formalismo y el estructuralismo son métodos, que, si bien son antiguos, no deben ser desechados por completo; sin embargo, estos tendrían que ser utilizados en el nivel universitario para estudiantes de lite- ratura, ya que son importantes en la metodología e historia de esta ciencia; mas no deberían ser empleados en la escuela secundaria, puesto que su complejidad puede hacer que los estudiante tiendan a confundirse cuando se lleven a cabo estudios de obras literarias. Durante el proceso de adquisición de la competencia literaria de los estudiantes, es importante que el docente no sea quien construya todas las interpretaciones, dado que ello conduciría a opiniones subjetivas de la literatura que deben ser evitadas, pues "si el profesor pretende anticipar el sentido esencial del texto está también cancelando de una forma autoritaria y dogmática la posibilidad de escucha" (Larrosa, 2003, p. 32).

Es necesario que el profesor de literatura reflexione sobre su quehacer, ya que, como afirma Petit (1999), "podemos interrogarnos más sobre nuestra propia relación con la lengua, con la lectura, con la literatura. Sobre nuestra propia capacidad para vernos afectados por lo que surge, de manera imprevisible, a la vuelta de una frase" (p. 167). En otras palabras, si el profesor quiere que el estudiante se cuestione a sí mismo después de haber leído una obra literaria, este también debe hacerlo; así existirá una empatía que permita una mejor relación con la literatura. 
La lectura ha de ser un proceso ameno en el que el estudiante disfrute de dicha actividad. Por lo tanto, es fundamental no imponer lecturas demasiado densas para el nivel secundario. Si se quiere lograr el objetivo de que los estudiantes desarrollen gusto real por la literatura a través de la experiencia estética, es necesario tener en cuenta sus opiniones, intereses e inquietudes; de esta manera, será más sencillo abordar un asunto que, a menudo, ha sido discutido por académicos y expertos en la temática.

En definitiva, el proceso por medio del cual se acoge y se actualiza la literatura, es un conjunto de producciones artísticas que son definidas por convencionalismos estético-culturales, el uso y los recursos expresivos del sistema lingüístico y la captación del signo lingüístico dentro de un texto literario. El reto es formar estudiantes competentes literariamente y la educación literaria es, especialmente, enseñar a reaccionar con base en el deleite producido por el texto, y es precisamente este postulado el que debe primar al momento de leer literatura: el placer. En consecuencia, "para transmitir el amor a la lectura, y en particular a la lectura literaria, hay que haberlo experimentado" (Petit, 1999, p. 168), pues, sin haber tenido la experiencia que suscita una obra literaria, será muy complejo transmitir este sentimiento. En otras palabras: hay que inocular la literatura.

\section{Referencias}

Altamirano, F. (2012). El contagio de la literatura: otra mirada de la didáctica de la literatura. La Palabra, (21), 21-32. Recuperado de: https://revistas.uptc.edu.co/index.php/la_palabra/article/view/961

Altamirano, F. (2016). Didáctica de la literatura: ¿cómo se contagia la literatura? La Palabra, (28), 155171. Doi: https://doi.org/10.19053/01218530.4813

Argüelles, J. (2009). Si quieres...lee. Contra la obligación de leer y otras utopías lectoras. Madrid, España: Fórcola.

Barthes, R. (1982). El placer del texto seguido por: lección inaugural de la cátedra de lingüistica del Collège de France pronunciada el 7 de enero de 1977. México, D.F.: Siglo XXI editores.

Bolívar, C. y Gordo, A. (2016). Leer texto literario en la escuela: una experiencia placentera para encontrarse consigo mismo. La Palabra, (29), 199-221. Doi: https://doi.org/10.19053/01218530. $\mathrm{n} 29.2016 .5710$

Borges, J. (1985). Coloquio. En Literatura fantástica (pp. 36-45). Madrid, España: Siruela.

Carvajal, E. y Moreno, M. (2009). El Estructuralismo en literatura: aportes y límites a las nuevas teorías estéticas y a la investigación en Didáctica de la Literatura. Enunciación, (14), 21-32.

Castro, O. y Posada, C. (1994). Manual de teoría literaria. Medellín, Colombia: Editorial Universidad de Antioquia. 
Chatman, S. (1978). Historia y discurso. Madrid, España: Taurus.

Chomsky, N. (1965). Aspects of the Theory of Syntax. Cambridge, Mass: MIT Press.

Colomer, T. (1991). De la enseñanza de la literatura a la educación literaria. Comunicación, lenguaje y educación, (9), 21-31.

Colomer, T. (2001). La enseñanza de la literatura como construcción de sentido. Lectura y vida. Revista latinoamericana de lectura. Recuperado de: http://www.mdp.edu.ar/humanidades/documentacion/licad/archivos/modulos/sem-a/eje4/A02.pdf

Colomer, T. (2005). Andar entre libros. México, D.F.: Fondo de Cultura Económica.

Culler, J. (1975). Poética estructuralista. Barcelona, España: Anagrama.

Eagleton, T. (1988). Una introducción a la teoría literaria. México, D.F.: Fondo de Cultura Económica.

Eco, U. (1992). Los límites de la interpretación. Barcelona, España: Editorial Lumen.

Eco, U. (1993). Lector in fabula. Barcelona, España: Editorial Lumen.

García-Dussan, E. (2016). Sobre el misterio estético en el texto literario: claves para una pedagogía de la literatura. La Palabra, (28), 141-154. Doi: https://doi.org/10.19053/01218530.4812

Genette, G. (1989). Palimpsestos: la literatura en segundo grado. Recuperado de: http://server1.docfoc. com/uploads/Z2016/01/09/SuCPV4JQzb/93c55b32e22d0f03add34afe79fa72b0.pdf

Higuera, G. (2016). De la estética de la recepción a la animación a la lectura: consideraciones teóricas para una propuesta de animación a la lectura literaria en espacios no convencionales. La Palabra, (28),187-199.

Iser, W. (1975). El proceso de lectura. Una perspectiva fenomenológica. Recuperado de: http://www. perio.unlp.edu.ar/catedras/system/files/iser._el_proceso_de_lectura.pdf

Jauss, H. (1981). Estética de la recepción y comunicación literaria. Punto de vista, (12), 34-40.

Jauss, H. (1992). Experiencia estética y hermenéutica literaria. Madrid, España: Taurus.

Jiménez, M. (2015). En torno al desarrollo de la semiótica literaria y el concepto de cultura. Dialogía, (9), 208-229.

Kirchof, E. (2009). Literatura como lenguaje: el legado de Roman Jakobson. Antares, (2), 60-74. 
Larrosa, J. (2003). La experiencia de la lectura: estudios sobre literatura y formación. México, D.F.: Fondo de Cultura Económica.

Larrosa, J. (2006). Sobre la experiencia. Aloma, (19), 87-112.

Lerner, D. (2001). Leer y escribir en la escuela: lo real, lo posible y lo necesario. México, D.F.: Fondo de Cultura Económica.

Mendoza, A. y Pascual, S. (1988). La competencia literaria: una observación en el ámbito escolar. Recuperado de: http://rodin.uca.es/xmlui/bitstream/handle/10498/7637/14024287.pdf?sequen$\mathrm{ce}=1$

Mendoza, A. (2004). La educación literaria. Bases para la formación de la competencia lecto-literaria. Málaga, España: Aljibe.

Mendoza, A. (2008). Función de la literatura infantil y juvenil en la formación de la competencia literaria. Alicante, España: Biblioteca Virtual Miguel de Cervantes. Recuperado de: http://www. cervantesvirtual.com/obra/funcin-de-la-literatura-infantil-y-juvenil-en-la-formacin-de-la-competencia-literaria-0/

Mendoza, A. (2008). La educación literaria. Bases para la formación de la competencia lecto-literaria. Alicante, España: Biblioteca Virtual Miguel de Cervantes. Recuperado de: http://www.cervantesvirtual.com/obra-visor-din/la-educacin-literaria---bases-para-la-formacin-de-la-competencia-lectoliteraria- $0 / \mathrm{html} /$

Ministerio de Educación Nacional. (1998). Lineamientos curriculares Lengua castellana. Recuperado de http://www.mineducacion.gov.co/1621/articles-339975_recurso_6.pdf

Montenegro de la Hoz, N. (2014). Changó, el gran putas: formas de resistencia e identidad esclavizada en los estudios poscoloniales. La Palabra, (24), 59-66. Doi: https://doi.org/10.19053/01218530.2501

Perdomo, A. (2005). «Sobre la enseñanza de la literatura y la formación de la competencia literaria». En M. Abril (Coord.), Lectura y literatura infantil y juvenil (pp. 149-170). Málaga, España: Aljibe.

Petit, M. (1999). Nuevos acercamientos a los jóvenes y la lectura. México, D.F.: Fondo de Cultura Económica.

Red de Bibliotecas. (2012). Luis Bernardo Yepes y sus muchos amores. Red de bibliotecas. Recuperado de: reddebibliotecas.org.co/diario/luis-bernardo-yepes-y-sus-muchos-amores

Rodríguez, O. (1977). Relaciones entre Lingüística y Literatura. Documentos Lingüísticos y Literarios, (1), 44-48. Recuperado de: http://www.humanidades.uach.cl/documentos_linguisticos/docannexe.php?id $=118$ 
Rosenblatt, L. (2002). La literatura como exploración. México, D.F.: Fondo de Cultura Económica.

Sierra Díaz, D.C. (2016). El Muntu: la diáspora del pensamiento filosófico africano en Changó, el gran putas de Manuel Zapata Olivella. La Palabra, (29), 23-44. Doi: https://doi.org/10.19053/01218530. n29.2016.5699

Sierra Díaz, D.C. (1987). Lenguaje y educación. Madrid, España: Cincel.

Todorov, T. (1978). Teoría de la literatura de los formalistas rusos. México, D.F.: Siglo XXI.

Yepes, L. (2016). Ciudadanía y lectura: cavilaciones. La Palabra. 1-11.

Vigotsky, L. (1972). La psicología del arte. Madrid, España: Barral Editores. 
